\title{
FACTS AND NARRATIVE - THE CONCEPT OF 4D CAPTURING OF HERITAGE BUILDING; A CASE STUDY OF SOMPUR MAHAVIHARA, BANGLADESH
}

\author{
Md Mizanur Rashid ${ }^{\mathrm{a},}$, Hafizur Rahaman ${ }^{\mathrm{b}}$ \\ ${ }^{a}$ Kulliyah of Architecture and Environmental Design, International Islamic University Malaysia - \\ mizanur@iium.edu.my \\ ${ }^{\mathrm{b}}$ Dept. of Architecture, Khulna University, Bangladesh - hrahaman@hmail.com
}

KEY WORDS: Heritage Building, Historical Narrative, Sompur Mahavihara, Virtual Knowledge Platform, 4d Capturing

\begin{abstract}
:
This study embarked upon a premise that considers architecture of building as a dynamic phenomenon. A building from its conception is susceptible to change due to various reasons. An historical building that is several hundred years old must have undergone through changes due to political, social, religious and most importantly functional reasons. Hence capturing building and its dynamic evolution is necessary to appreciate its architecture as well as its heritage value. Whereas the conventional method of fact based historiography only captures the building in particular moment. It makes architectural historians to become perplexed over to which particular moment to be documented. It is a great challenge for the architectural historians to bring back these dynamic characters of the building that are mostly inconspicuous in nature from this point of time. In this situation the historical discourse also remains elusive and blurred. The idea of $4 \mathrm{~d}$ capturing comes in front in this scenario. Current research would venture into this emerging idea to record the architecture of the early period. This paper highlights the need for a flexible tool to capture this dynamic character of the building. By citing the case study of the $7^{\text {th }}$ century Buddhist Monastery in Bengal, this paper thus argues for the need of capturing the narrative of a historical building than the facts to get a complete picture of its architecture. This study aims at capturing the narrative of Sompur Mahavihara, the UNESCO World Heritage site in Bangladesh, which is currently in ruinous condition. However, it's few hundred years life suggests that as architecture it was subject to change due to different reasons, mainly political, religious and rituals. Being a monument that belongs to the flourishing phase of a society, traditionally this monastery architecture certainly played a role as a stage for religious and political pageantry as well as different religious performances. As architecture it works as complex process of interaction of different layers of ideas, agendas and authorship through time. This paper would further explore different tools for historians to capturing this process of interaction and preserving/ conserving the narrative of this building using virtual modelling.
\end{abstract}

\section{INTRODUCTION}

\subsection{Scenario}

Architecture is a process that accumulates collective memories and the material culture and practice of its users through time. It is a self repository of the collective memory imbuing meaning to the historical facts. The physical articulation and transformation of architecture is directly connected with the social-politicalcultural aspiration of its inhabitants. Kalay (Kalay and Marx 2001) pointed out that 'Places are created through inhabitation. People imbue space with social and cultural meaning, transforming mere space into a place'. Hence, an architectural heritage is something more than the physical form. Symbolically a building is a 'place' for performing different activities and meaning and values. Depending on the hierarchic order of the society, it works as symbolic centre of staging the role and influence of its owner to the society. In other words, it is the centre stage, from where the owner establishes its charisma by stressing the symbolic connection between the symbolic values the individual posses and their relation to the active centre of the social orders (Shils, 1965). This is vital for the persons, who are at the centre of the political, social or religious order of the society. Hence building a religious monument is not merely an act of providing spaces for accommodation for religious performances, but it works as pageantry for the kings and the priests to its citizens. The spaces inside religious structures are precisely guided by the everyday use as well as rituals and performances. To understand the architecture of the monastic complexes through time, mere three dimensional study of its architecture would not be sufficient. It requires creating a platform that can capture the building and its changes through time. Hence researchers need to know how the design of the building is conceived through the organization of different spaces within it through time.

For this instance, this particular case, the Sompur Mahaviahara in Bangladesh has gone through radical changes in terms of its form, function, architecture and tectonics. The brief history of the building advocates that the conventional way of heritage documentation might fail to capture the actual essence of the building. To appreciate its heritage value and to convey the history of the building to the next generation historical research requires a kind of documentation that not only capture the three (3) dimensional aspect of the building and its form but also capture different phases and changes through time, which in this research is called as ' $4 \mathrm{D}$ documentation'.

\subsection{The Problem}

The most striking architectural feature that distinguished Sompur Mahavihara from the other Buddhist monasteries found in South Asia is the central cruciform structure (Fig. 1). Hence most of the debates generated hitherto on the architecture of Sompur Mahavihara are centred on the missing superstructure as well as its layout, configuration and architectural details. The ruin of the

\footnotetext{
* Corresponding author. This is useful to know for communication with the appropriate person in cases with more than one author.
} 
structure rises upward in a tapering mass of three receding terraces, which reaches a height of 23 meters. Each of these terraces has a circum-ambulatory passage around the monument. At the topmost terrace (of the existing ruin) there were four antechambers on the projecting arms of the cross. The overall design of this complicated architecture is centred on a square hollow shaft, which runs down from the present top of the mound to the level of second terrace. Sompur Mahavihara is definitely the mostly studied historical monument in Bengal. The threedimensional articulation of the missing superstructure of the central edifice remains at the centre of the debate that led to several attempts of theoretical reconstruction by different scholars (Rashid 2008). However, the nature and the extent of the earlier studies are not sufficient enough to substantiate the historical discourse. The reason could be manifold, but the most important one is the non-availability of substantial amount of resource including a comprehensive architectural documentation at the disposal of the researchers. Tacit historical records coupled by the fragmented archaeological remains that are mostly at foundation level have perplexed the situation. Consequently, most of the works done so far are mainly limited on the findings of the archaeological excavation and studying the artifacts from the archaeological perspective. Hence the history of Buddhist architecture in Bengal is yet to be recovered from the amnesia of a millennium.
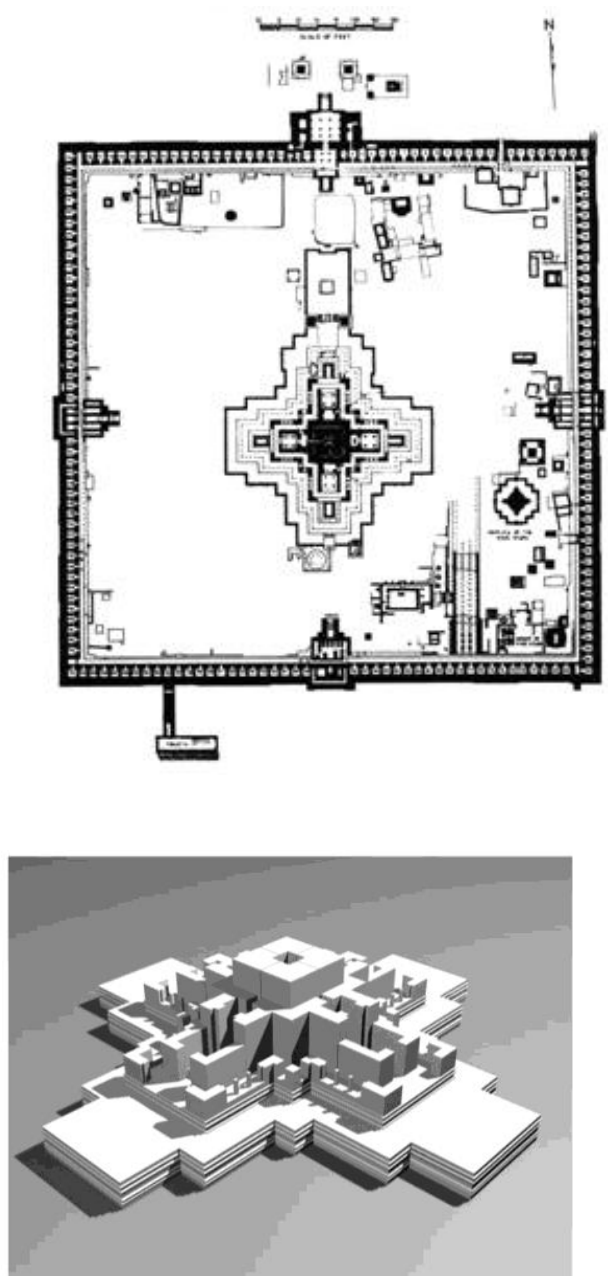

Fig.1: Plan of Sompur Mahavihara (Source: Department of Archaeology, Govt. Of Bangladesh) and the reconstructed model of the central structure (Rashid 2008)

\section{FROM CONSTRAINT TO OPPORTUNITY}

\subsection{Beginning}

The earlier attempts of understanding the architecture of this monastery through theoretical reconstruction have failed to offer a cogent resolution. The reason seems to be the over reliance on the scanty and fragmented resources in hand. However, it is felt that the main problem is not the scarcity of resources rather it is the absence of a scientific framework to collate all the resources in hand. At this instance it is seemingly difficult to depend solely on materials that are available at first hand to demonstrate a continuous narrative of the architecture of this monument but not impossible. This lack of physical resources could be transformed into opportunities than constraints for followings reasons.

I. The lack of sufficient physical resources may be a hindrance to demonstrate a lucid description of architecture. Nevertheless, at the same time it offers a 'Tabula Rasa' by deconstructing any preconceived notion. The apparent amnesia could be seen as a great opportunity to understand the building process of the monument from a very neutral point of view. It may provide a very accurate understanding of the individual architecture but it would lessen the risk of deviation because of the wrong interpretation of the archaeological ruins. Especially for the case of Sompur Mahavihara, where most of the architecture is missing this situation could be used to look at the problem from a broader perspective and in a much flexible way. To optimize the extent of this the focus of the study should be turned from the product to the process.

II. It further opens up a ground for accommodating the earlier studies and contesting hypotheses. The apparent discrete nature of the approaches of these earlier works does not necessarily indicate a disjunction. Rather it demonstrates the array of possibilities of looking at the problem. Putting them together in a common platform through a critical analysis may give us much elucidating picture of the problem. The idea is not to debunk them or the assumptions upon which they are based, but to develop an integrated approach that includes all the possibilities and scopes. Eventually it may establish a theoretical framework for further study by accepting, criticizing and refuting some of these earlier assumptions, which we would discuss later..This study can be considered as an addition to the existing body of knowledge. By digitizing the historical data and the hypotheses in a proper virtual database, the terrain will not only be much richer but also offer a much wider scope to fill up the lacuna.

III. As architecture, this building is a part of the material culture of this region. The determinants of the material culture of particular location such as the tradition and world view of the people, the custom of reverence, symbol and rituals of expressing status, gender relationship, the sepulchral tradition etc. exist in a layered manner. These layers are not only overlapped with each other but also maintain an osmotic relationship of continuous transformation of ideas and themes in between them. Hence, the religious architecture is a result of a contestation of multiple themes, ideas and authorship. Because of the amorphous nature of the religion, Buddhist religious 
architecture is much susceptible to changes due the cultural paradigm both in terms of form and meaning (Rashid 2006). This is not as simple as borrowing some elements from the other or adopting some style of expression. It is deeply rooted at the very conception of architecture or piece of art. Understanding the process and discerning the layers would help to understand the architecture as well. That requires the history be looked in a more dynamic way and use all the available tools. It necessitates the data to be sought from different sources and to evaluate the problem of architecture from a much broader perspective.

IV. Virtual modeling can be used as a useful tool for relating the intangible data with the tangible ones as well as multiple verification and criticism. In this study it is not directed towards the end product as photographic realization of the original structure of Sompur Mahavihara. On the contrary, it concentrates more on developing a method of evaluation and synthesis to conceptualize the formal expression of the structure and its changes through time. Initially the virtual reconstruction is directed to reconstruct the possible 3 dimensional articulation of the existing remains of the structure, which would be used as the basis for further study on its history ( Rashid and Heng 2006) . In the later phases, which is currently in progress the 3 dimensional model of the building will be put under the historical timeline to capture the changes. As the historical narrative of the building is currently blurred and ambiguous, the virtual portal will work as platform to accommodate all the currently available data. Hence the present study may end up with several theoretical models of the Sompur Mahavihara based on different contesting hypotheses. This process of theoretical restoration and interpreting available information is a continuous one. What would not be found today can be kept for the future to comprehend, provided that the present information is not destroyed (Forte \& Silliotti 1997). Even the correction and criticism and debate can be accommodated by the successive reconstruction. It is perhaps the most flexible means using all the available resources that are apparently inconspicuous in nature.

\subsection{Historical Scan: digitizing the history:}

As the nature of the primary historical data regarding this building is tentative in nature, it was felt that the priority should be to understand the process through which architecture is conceived and materialized. Hence a cross disciplinary approach was adopted at the beginning. Initially all the historical data that might have some relevancy regarding the architecture of the building from different disciplines was digitized and collated in a systematic way. As it was mentioned earlier that the information that are available regarding the monument was scanty and fragmented. Whatever exists today is also confabulated to some extent. Hence a rigorous scrutiny of the data was done to examine the minute clue that might affect the architecture of the building. Later all the relevant data were linked in scientific way to reconstruct the possible shape of the building. In a nut shell this process of digitizing and scrutinizing the historical data can be termed as Historical Scan. It started from a much broader perspective to portray a broader picture of the development Buddhist religious buildings through time and space and tried to locate our case within this. Then it gradually zoomed down by discerning each of the layers one after another. The attempt was to develop a framework to link all the available primary data and the assumptions based on that. The threads of all the available resources were linked together in one end to construct the bigger scenario. The other end of the thread was kept open for inflow of the future resources so that the model or the proposal can be modified when newer resources would be available.

The initial nature of the linked data framework was more flexible and tentative. The strategy was to proceed in stages. The method was to start initially from a broader framework and then gradually descend to the next levels one after another. The inference deduced in one level actually determined what type of information should be looked for and what type of resources should delved in at the next level. Hence with the progress of the research, the overall frame-work was getting more concrete. In the schematic diagram described in the fig. 2, a comparison was done between the tentative framework and the actual course of the study. It would provide a clear idea about different levels of the actual study, their objective, findings and interrelationships. In the earlier stage of the historical scanning process it was concerned about the historical study to define the structure itself in terms of its purpose and use, and in later stage it scanned through all the historical resources to resolve the technicalities of the theoretical reconstruction of the monument. The outcome of this process is the Virtual Knowledge Platform (VKP) that eventually would lead to the reconstruction of the architecture of the building.

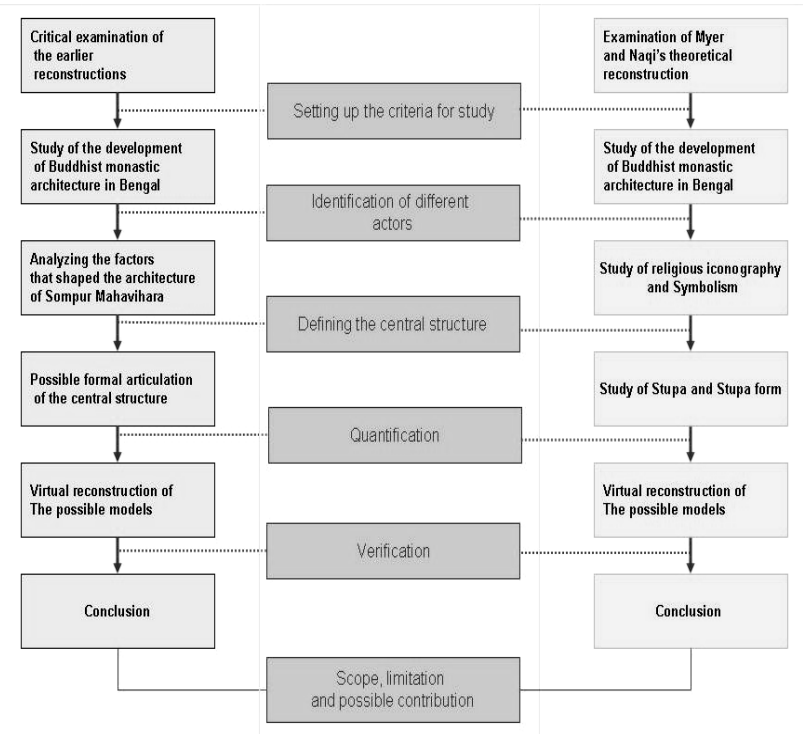

Fig.2: A comparison between the initial research outline and actual course of study (Rashid, Hafiz, 2011)

\section{VIRTUAL KNOWLEDGE PLATFORM}

\subsection{Reconstruction}

This Virtual Knowledge Platform (VKP) developed in earlier stage is actually the database that collates all the available information regarding this building from different sources and then deduces logical inference by using this information. 
Because of the fragmentary nature of the information there were some grey patches in the platform. However it did not hamper the objective of the research. The problem was looked into from an architectural perspective and the gaps were filled by using architectonic reasoning. This might not give a definite solution but it shaped the discourse and the data base, which was earlier amorphous. Now it is clear that what type of information to be looked for at and how it might change the form of the building. All the available information were arranged and organized in a systematic manner for the next level of study. The main contribution of this platform is it interactive and flexible nature that is open for necessary feedback in the second phase and refinement of the virtual model. The Virtual Knowledge Platform (VKP) for this case is described in the fig. 3. The most important aspect of the VKP is that it not only relies on architectural or archaeological sources, rather it adopted a cross disciplinary approach. Hence any small discovery at any discipline can be used in this framework to observed how it will affect the three dimensional expression of this structure. It also helped the future researcher to be aware of the type of information to be looked for and how this should be used to understand the architecture of Sompur Mahavihara. This framework also demonstrates the possible scope for future extension of the research that would engender further refinement the virtual model. However, the ends are kept open to accommodate the outcome of the future studies in these areas within this framework to verify the model at more detailed level. The most interesting part is that VKP itself is flexible and can be modified in future if necessary. This is a continuous process and would go on, as more resources are made available.

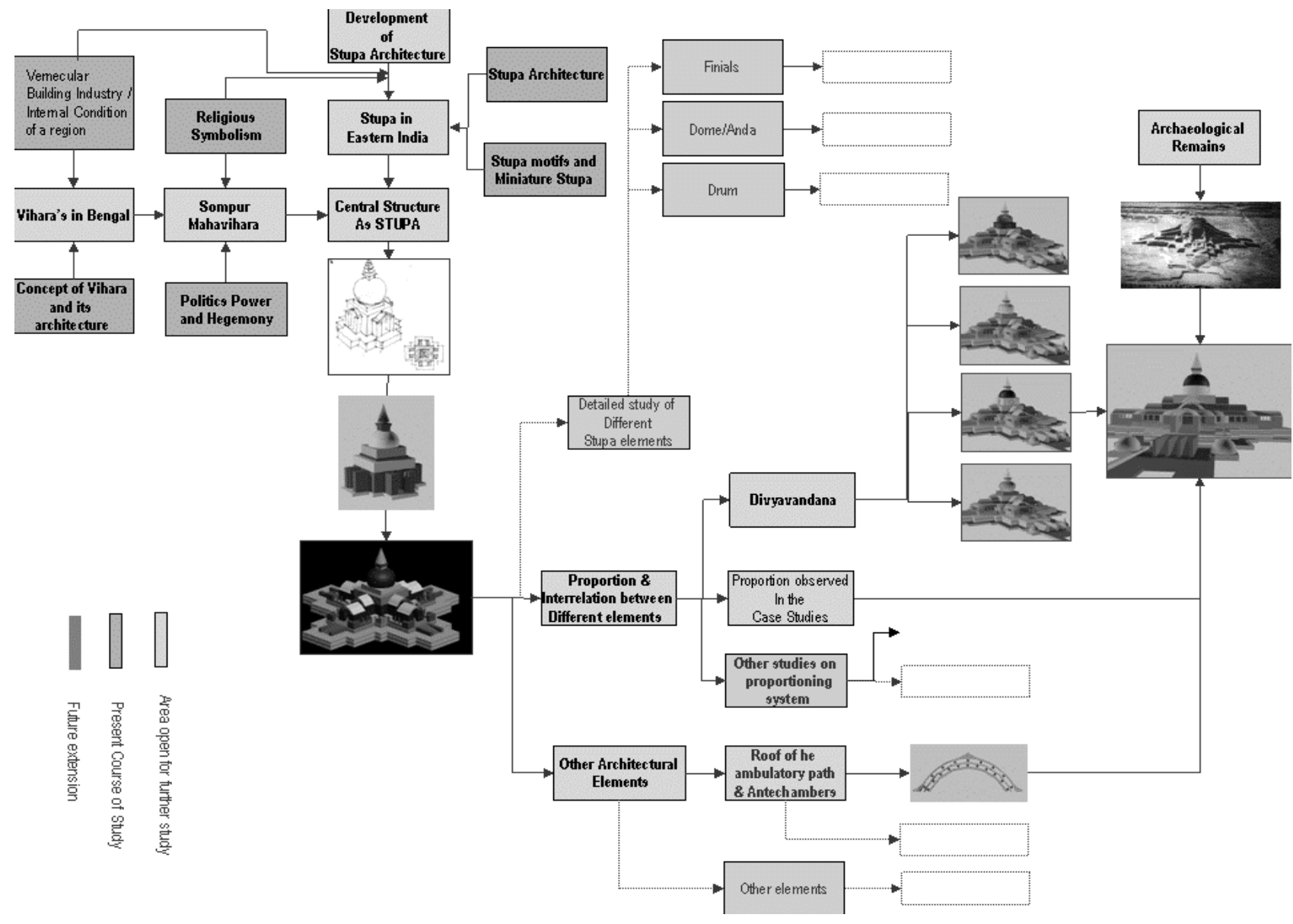

Fig. 3: Scheme showing the Virtual Knowledge Platform ( VKP) for Sompur Mahavihara (Rashid, 2006)

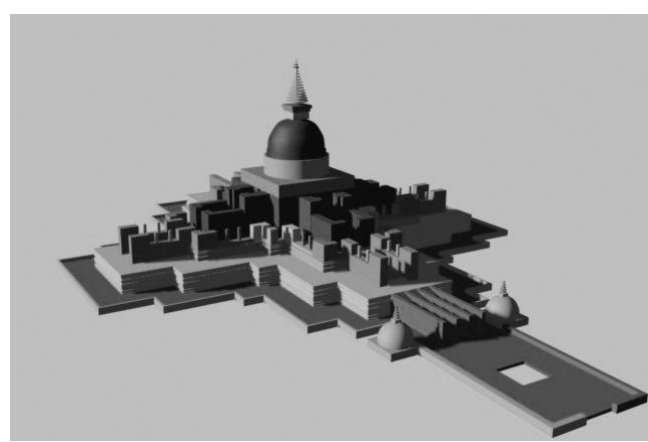

Fig.4: Reconstructed model based on the VKP that has the closest match with the existing ruins (Rashid, 2006) 


\subsection{Revisiting the Past: Narrative of the building}

The earlier virtual reconstruction has only captured the building in its last occupation level, as we have used the existing ruins of the building as the only tangible historical evidence. However, the archaeological discovery (Dikhshit 1938) and other historical records (Majumder 1946) Substantiate that this building has gone through several vicissitudes along with the political and social upheavals. The question that becomes evident whether this capturing a particular moment is enough to disseminate the true heritage value of the monument? Is this enough to minimize the distance between a heritage building and public observed? Especially, in the case of Sompur Mahavihara , where the heritage building is presently ruined and limited amount of archaeological resources that are available to fill up the lacuna. Now the question that comes in front is how to use this model for further feedback and refinement to enliven the memories of the heritage back to the people and minimizing the distance between the people and the heritage. In this juncture the concept of 'Virtual Heritage' has emerged. Roussou (2002) described Virtual Heritage as an intersection of virtual- reality and cultural heritage. She further defined the functions of virtual heritage to facilitate the synthesis, conservation, reproduction, representation, digital processing and display of cultural evidences. There already exists example of Virtual Archaeology (Barceló 2000), where some archaeological sites have been reconstructed for three dimensional experiences. Nevertheless whether they are playing a successful role for heritage conservation is questionable. From the earlier examples it seems that that the end product (reconstructions of the lost buildings or sites) remains within the domain of academia. A few of them are merely published in websites, media or open to public spaces in museums. However, the broader definition of Virtual Heritage demonstrates a process that involves not only different disciplines (e.g. Architecture, Computation, History, Heritage and Museum studies, Cultural Studies etc) but a wider spectrum of people. It certainly needs a participatory approach to fully recover the memories of the building.
Dourish (Dourish 2001) also emphasized on participation, task accomplishment and practical action for an effective embodiment with the environment. As successful interactive experience can only be achieved while a person feels interest with the content, poses empathy with it and finally can imagine the alternate reality (Schell and Shochet 2001) and that can only be achieved through proper interaction.

An architectural heritage is something more than the physical form. A building is a place for doing different activities. Especially spaces inside a religious building, e.g. Sompur Mahavihara, are precisely guided by the rituals and performances. To understand the architecture of this monument, mere virtual reconstruction of the three dimensional from would not be sufficient. In order to create virtual environment embodying the essence of place is inevitable. Usually the role of 'Place' is virtual environments has been as a locator of objects (Champion and Dave 2002). But Kalay (Kalay and Marx 2001) pointed out that 'Places are created through inhabitation. People imbue space with social and cultural meaning, transforming mere space into a place'. Hence we need to know how this design of the building is conceived through the organization of different spaces within it. Being a monument that belongs to high Tantric phase of Buddhism in Bengali, the architecture of this monument was certainly determined by Tantric rituals and rites (Rashid 2006) . The movements of monks within the complex, their daily life and periodic ritual performances had significant importance in the spatial organization of Sompur Mahavihara. Hence to recover of the memories of this building, it is required to examine the aspects how spaces were generated, interpreted and interconnected with respect to the daily activities of the monks and the ritual performances. Analysis of different activities and the ritual performances within the monastery should be equally emphasized in the Virtual Knowledge Platform (VKP) focusing on the aspects of spatiality. This VKP should be more interactive and be able to narrate the story of the building along with the facts to keep the memories alive and protect the true heritage value of the Monument.

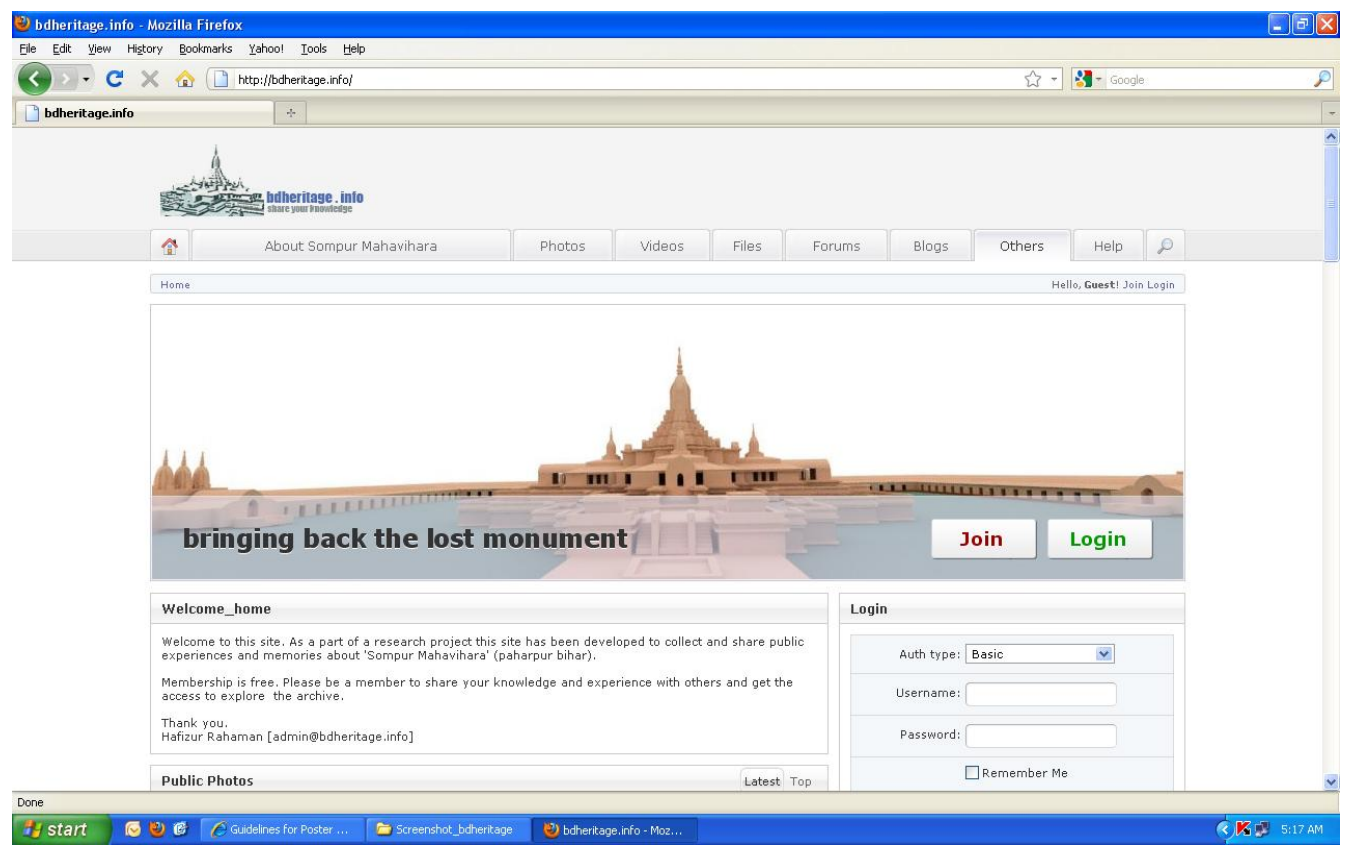

Fig. 5: Screenshot of the web portal . (Rashid, Hafiz, 2011) 


\section{THE CONCEPT OF 4D CAPTURING}

The idea of more interactive and flexible Virtual Knowledge Platform (VKP) for heritage building leads to the concept of 4D capturing (4DC) of the building. A scrutiny of the VKP for Sompur Mahavihara demonstrates that architecture is susceptible to change due to various reasons (Rashid and Heng 2006). A building that is few hundred years old had passed through different changes through time due to the changes of conditions. Throughout its life time a building has undergone several changes due to political, social, religious and most importantly functional reasons. Hence capturing building and its dynamic evolution is necessary to appreciate its architecture as well as its heritage value. The conventional method of conserving or documenting heritage building only captures the building in particular moment.

Therefore, it was felt that the VKP leading towards capturing the building in particular moment in the history and reconstructing one particular virtual model of the building seems problematic in a case like Sompur Mahavihara, where the lifespan of the building stretches over a period of 400 years (eighth century AD to eleventh century AD). It advocates further elaboration of the VKP to capture the actual essence of the building. To appreciate its heritage value and to convey the history of the building to the next generation it needs a kind of documentation that not only captures the 3 dimensional aspect of the building and its form but also capture different phases and changes through time. In this study it is termed as 4D capturing (4DC). Interaction with people and peers and collating the feedback further extension of the VKP is necessary. For this a web portal would be an excellent tool to convey the changes of the building through time to the user.

This website would disseminate the use of this emerging idea of virtual technology to record the architecture of the monument of Sompur Mahavihara in a comprehensive manner.

This research has combined architectural history with other disciplines using the virtual technology as tool. The scholars in architectural history could take care of the architectural part of the study, whereas for the other part like people's participation with the model the study relied mostly on the virtual portal or the website that has been developed in the second phase. For the purpose of extending the scope of the VKP and the development 4DC, the approach and the overall research procedures are restructured into three major parts according to the research objectives.

1. Developing a comprehensive and interactive virtual model of Sompur Mahavihara: The major objective of this part of the study to develop a holistic and comprehensive architectural model of the lost heritage building, which would be used in the later part of the study. Based on this study a preliminary spatial model has been developed for this lost monument. This model would be compared with the previously developed formal model to develop the final interactive virtual model for public's interaction. This model would not be photo realization of the original monument as Osberg (1997) identified that abstract drawing/ view is more effective and better understood than the highly realistic one. Hence, it concentrates more on developing a method of evaluation and synthesis to conceptualize the Architecture of the monument.
2. Bringing/conveying this interactive model to a wider spectrum of people by using the website: In this part a website www.bdheritage.info (Fig 5) has been developed to convey this model to people from different spectrum for interaction and feedback. These models along with the other earlier reconstructions by different scholars have been published in website to bring it to a larger community of scholars and other people. This website also works as virtual database where all the relevant information, research publication, images; videos are uploaded for the user. The idea is to provide all the relevant information regarding the monument within the click of the user. Hence a user can use the database for his own purpose at the same time upload his ideas through blog or uploading in the relevant section. At the same time it is planned to erect smaller installation in different public places like Museum, Educational Institution and libraries so that the aspiring students and general public people can participate and interact with the model. Unlike the most Virtual heritage model this model would incorporate the cultural information or the 'intangible part of the heritage' (associated folk tales, local believes, religious believes, oral history etc) with the tangible one. It would not only be restricted with the developer's own narrative rather the users could personalize the interface or changed the story board if needed. These models or installation are continuously monitored for collating feedback and accommodating, altering and even sometime rejecting the ideas for further modification of the model and framework of knowledge. Interestingly a reasonable number of feedbacks have been collected from the user some of $\mathrm{w}$ them are really valuable and contribute significantly for further modification. Some of the information/documents that initially were not approachable by the researcher during the first reconstruction have been collected through the website and currently under scrutiny of the researchers for further modification of the model. However, as the work is still under progress the publication of final modified model is still out of the scope of this paper.

3. Collating the feedback and re-organizing the VKP for 4DC: In this part of the study would collate all the feedback regarding architecture of this heritage from the different input sources and then deduce logical inference by using this information. The problem was looked in a more architectural way and fill up the gaps using architectonic reasoning that eventually leads to reconstruct the historical narratives of the building. A virtual time line of the building with different relevant linked data base will be the final outcome of the study. Once the 4DC model will be developed, the user can easily access to any phase of the building's lifespan and get necessary records of that particular point of time including the $3 \mathrm{~d}$ model. This 4DC model could be accessed through the modified web portal or in situ. For onsite interface, visitors can access the VKP through smart phone application. For a simpler application initially, a small Wi-Fi network would be developed in the present archaeological site. The URL of the web portal and other $3 \mathrm{~d}$ and augmented reality images of the monument of different phases will be coded with Quick Reference Code (QRC). These QR codes will be placed in different part of archaeological ruins. Any visitor, who wished know about the spatial aspect of any aspects or any information 
regarding the monument can easily download the information. At the beginning it might not give concrete information of the original form of the building but it generates a process of learning and evaluation. The main contribution of the study is not only to develop this interactive framework of information that is open for necessary feedback future and refinement of the virtual model, but to educate and attach the people with the lost heritage and let them participate in the process of conservation of this cultural heritage and preserve the memories.

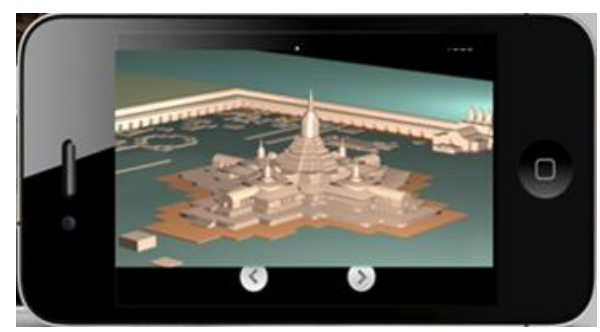

Fig 6: Information regarding the lost Monument can be disseminated through the smart phone application.

\section{CONCLUSION}

This research is currently a work in progress. This study is designed to address two fundamental problems. Firstly, the problem that lies inherently with the documentation of the lost archaeological monuments. A historical building is a memory of past and it should be preserved for its particular location in the history. However, is it only the commemorative value that should be into account? Actually a monument poses wide ranges of values, both tangible and intangible, towards itself. The physical documentation or conservation in its true form not only ensures the formal characteristics of the monument, but at the same time put a considerable impact on the others, especially on the intangible aspects. To preserve this whole set of values a detail inventory of information is needed before going into a physical documentation and conservation of the monuments, because if the meanings are not recorded properly it becomes hazardous enough to destroy the whole set of tangible as well as intangible values. This phenomenon is of utmost importance in the cases where the architecture of the building changes through time or become susceptible to destruction because of less durable materials like brick or timber. The second problem is to disseminate the heritage building to the common people with proper value. People can only participate in the conservation of the heritage once the whole set of value and meaning was presented to them. For the case of building that is currently ruin at foundation level there is no other way than digital technology and virtual modelling to bring it back to the people. Hence, it is more practical and rational to go for 4DC or architectural narrative than fact based documentation that captures the time line of the building and the dynamic historical process in a holistic and comprehensive manner. Apparently it seems difficult to grasp the complex history of the successive changes made to the building due to time and other requirement. Use of digital technology could help in this aspect a lot, which is one of the components of this ongoing research. This technique would allow creating models with complete reliability from the original architectural structure. In future it could incorporate the 4DC in multimedia applications, as a mean of conveying information for educational purposes, which is the end goal of this project.

\section{REFERENCE}

\section{Reference from Books:}

Dikhshit K.N.,1938, Paharpur, Memoirs Of Archaeological Survey Of India. Delhi, Vol. 55.

Dourish, P., 2001, Where the action is: the foundations of embodied interaction. MIT Press, Cambridge, Mass.

Forte, M. and Silliotti, A.,1997, Virtual Archaeology, New York,

Majumder, R.C. ed., 1946, The History of Bengal, Dhaka.

Osberg, K.M., 1997 Constructivism in practice: the case for meaning-making in the virtual world, University of Washington.

Roussou, M., 2002 ,'Virtual Heritage: From the Research Lab to the Broad Public' In Virtual Archaeology, pp. 24-25.

Schell, J. and Shochet, J. Designing Interesting Theme Park Rides ( 2001)

\section{Reference from Journal:}

Rashid, M.M., 2008, 'Defining the Central Structure Of Sompur Mahavihara' in The International Journal of Bengal Art, Vol. 11, International Centre for Bengal Arts, Dhaka, pp. 212-25.

Rashid, M.M., 2006, 'The Conception Of The Architectural Layout Of Sompur Mahavihara: An Analysis Of Cultural And Religious Symbolism' in The International Journal of Bengal Art. Vol. 9, International Centre for Bengal Arts, Dhaka, pp. 97-110.

Shils, E., 1965,'Charisma, Order and Status' in Amercian Sociological Review, American Sociological Association.

\section{Reference from Conference Proceedings and others:}

Barceló, J. A., 2006 'Visualizing What Might Be. An Introduction to Virtual Reality in Archaeology' in Virtual Reality in Archaeology 843, pp. 9-36

Champion, E. and Dave, B., 2002, 'Where is This Place', Thresholds Between Physical and Virtual, Proceedings of ACADIA 2002, pp.87-97.

Kalay, Y. and Marx, J, 2001. 'Architecture and the Internet: Designing Places in Cyberspace' in Reinventing the Discourse, Proceedings of ACADIA 2001, pp. 230-240.

Rashid, M.M, and Heng, C.K., 2006, 'Confronting History and Amnesia; A case study of virtual reconstruction of Sompur Mahavihara at Paharpur, Bengal' in Contested Terrain, ed. T. McMinn, John Stephens, S. Basson, Proceedings of the XXIII Annual Conference of The Society of Architectural Historians of Australia and New Zealand, pp.377-383

Rashid, M.M. and Rahaman, Revisiting the past through Virtual Reconstruction; The case study of the Grand Monuments at Paharpur, Bengal. Pallatium; Virtual Palaces Workshop I , Catholic University of Leuven, Belgium 
International Archives of the Photogrammetry, Remote Sensing and Spatial Information Sciences, Volume XL-5/W2, 2013 XXIV International CIPA Symposium, 2 - 6 September 2013, Strasbourg, France 